\title{
Fixed points of mappings defined on spaces with distance
}

\section{Mitrofan M. CHOBAN}

\section{ABSTRACT.}

In the present article we study distinct metrical structures guaranteeing the existence of fixed points for a given mapping (Propositions 3.4 and 5.9, Theorems 4.1 and 7.3, Corollaries 2.1, 3.3, 4.4, 4.7, 5.10, 6.12, 6.13). Some examples are proposed (Examples 1.4, 4.9, 6.12).

Acknowledgments. The author is grateful to Professor Vasile Berinde for interesting problems and valuable suggestions and to the Professors Dumitru Cozma and Vitalie Puțuntică for the useful discussions.

The main results of the present article were presented in the communication at the Eight Congress of Romanian Mathematicians [19].

\section{REFERENCES}

[1] Alexandroff, P. and Urysohn, P., Une condition nécésare et suffisante pour qu'une classe (L) soit une classe (D), C. R. Acad. Paris, 177 (1923), 1274-1276

[2] Alexandroff, P. and Urysohn, P., Mémoire sur les espaces topologiques compacts, Verh. Akad. Wetensch. Afd. Naturk. Sect. I, Amsterdam, 14 (1929), 1-96

[3] Arhangel'skii, A. V., Mappings and spaces, Uspehi Matem. Nauk, 21 (1966), vyp. 4, 133-184 (English translation: Russian Math. Surveys, 21 (1966), No. 4, 115-162)

[4] Bakhtin, I. A., The contraction mapping principle in almost metric spaces, Funct. Anal., Ulianovskii Gosud. Pedag. Inst., 30 (1989), 26-37

[5] Berinde, V., Problem 1, 06 January 2015 (Private communication)

[6] Berinde, V., Generalized contractions in quasimetric spaces, Seminar on Fixed Point Theory, Preprint No. 3 (1993), Babeş-Bolyai Univ., Cluj-Napoca, 3-9

[7] Berinde, V., Error estimates for a class of $(\delta, \varphi)$-contractions, Babeş-Bolyai Univ. Facult. Math. Comput. Sci. Res. Sem., Preprint No. 3 (1994), 3-10

[8] Berinde, V., Generalized contractions in $\sigma$-complete vector lattices, Univ. u Novom Sadu, Zb. Rad. Prirod.-Mat. Fak. Ser. Mat., 24 (1994), No. 2, 31-38

[9] Berinde, V., Approximating common fixed points of noncommuting discontinuous weakly contractive mappings in metric spaces, Carpathian J. Math., 25 (2009), No. 1, 13-22

[10] Berinde, V., Common fixed points of noncommuting discontinuous weakly contractive mappings in cone metric spaces, Taiwanese J. Math., 14 (2010), No. 5, 1763-1776

[11] Berinde, V. and Choban, M. M., Remarks on some completeness conditions involved in several common fixed point theorems, Creat. Math. Inform., 19 (2010), No. 1, 1-10

[12] Berinde, V. and Choban, M. M., Generalized distances and their associate metrics. Impact on fixed point theory, Creat. Math. Inform., 22 (2013), No. 1, 23-32

[13] Branciari, A., A fixed point theorem of Banach-Caccioppoli type on a class of generalized metric spaces, Publ. Math. (Debr.), 57 (2000), 31-37

[14] Cauty, R., Solution du probleme de point fixe de Schauder, Fund. Math., 170 (2001), 231-246

[15] Chittenden, E. W., On the equivalence of écart and voisinage, Trans. Amer. Math. Soc., 18 (1917), 161-166

[16] Choban, M. M., Fixed points for mappings defined on pseudometric spaces, Creat. Math. Inform., 22 (2013), No. $2,173-184$

Received: 29.03. 2015; In revised form: 22.09.2015; Accepted: 04.10.2015

2010 Mathematics Subject Classification. 54H25, 54E15, 54H13, 12J17, 54E40.

Key words and phrases. Symmetric, $N$-distance, $F$-distance, $H$-distance, $A F$-distance, $B$-symmetric, fixed point. 
[17] Choban, M. M., Selections and fixed points theorems for mapping defined on convex spaces, ROMAI J., 10 (2014), No. $2,11-44$

[18] Choban, M. M., Fixed points for mappings defined on generalized gauge spaces, Carpatian J. Math., 31 (2015), No. 3, 313-324

[19] Choban, M. M., Distances, boundedness and fixed point theory, The Eighth Congress of Romanian Mathematicians, Alexandru Ioan Cuza University of Iaşi , June 26 - July 1, 2015, Iaşi, România, Iaşi, 2015, pp. 57

[20] Choban, M. M. and Calmuțchi, L. I., Fixed points theorems in multi-metric spaces, Ann. Acad. Rom. Sci. Ser. Math. Appl., 3 (2011), No. 1, 46-68

[21] Choban, M. M. and Calmuţchi, L. I., Fixed points theorems in E-metric spaces, ROMAI J., 6 (2010), No.2, 83-91

[22] Czerwik, S., Fixed Points Theorems and Special Solutions of Functional Equations, Katowice, 1980

[23] Engelking, R., General Topology, PWN, Warszawa, 1977

[24] Frink, A. H., Distance functions and the metrization problem, Bull. Amer. Math. Soc., 43 (1937), 133-142

[25] Granas, A., and Dugundji, J., Fixed point theory, Springer, Berlin, 2003

[26] Jleli, M., and Samet, B., A new generalization of the Banach contraction principle, J. Inequal. Appl., 2014 (2014), 1-8 doi:10.1186/1029-242X-2014-38

[27] Kikina, L., Kikina, K. and Vardhami, I., Fixed point theorems for almost contractions in generalized metric spaces, Creat. Math. Inform, 23 (2014), No. 1, 65-72

[28] Măruşter, S. and Rus, I. A., Kannan contractions and strongly demicontractive mappings, Creat. Math. Inform, 24 (2015), No. 2, 171-180

[29] Nedev, S. I., o-metrizable spaces, Trudy Moskov. Mat. Ob-va, 24 (1971), 201-236 (English translation: Trans. Moscow Math. Soc. 24 (1974), 213-247).

[30] Nedev, S. and Choban, M., On the theory of o-metrizable spaces, I, Vestnik Moskov. Univ. Ser. I Mat. Meh., 27 (1972), No. 1, 8-15 (English translation: Moscow University Mathematics Bulletin 27 1973, No. 1-2, 5-9)

[31] Nedev, S. and Choban, M., On the theory of o-metrizable spaces, II , Vestnik Moskov. Univ. Ser. I Mat. Meh.,27 (1972), No. 2, 10-17 (English translation: Moscow University Mathematics Bulletin 27 (1973), No. 1-2, 65-70)

[32] Nedev, S. and Choban, M., On the theory of o-metrizable spaces, III. Vestnik Moskov. Univ. Ser. I Mat. Meh., 27 (1972), No. 3, 10-15 (English translation: Moscow University Mathematics Bulletin 27 1973) No. 3-4, 7-11)

[33] Niemytzki, V., On the third axiom of metric spaces, Trans Amer. Math. Soc., 29 (1927), 507-513

[34] Niemytzki, V., Uber die Axiome des metrischen Raumes, Math. Ann., 104 (1931), 666-671

[35] Oprea, A. M., Fixed point theorems for multivalued generalized contractions of rational type in complete metric spaces, Creat. Math. Inform, 23 (2014), No. 1, 99-106

[36] Patriche, M., Equilibrium in games and competitive economies, Editura Academiei Române, Bucureşti, 2011

[37] Păcurar, M., Berinde, V., Borcut, M. and Petric, M., Triple fixed point theorems for mixed monotone Prešić-Kannan and Prešić-Chatterjea mappings in partially ordered metric spaces, Creat. Math. Inform, 23 (2014), No. 2, 223-234

[38] Rus, I. A., Petruşel, A. and Petruşel, G., Fixed point theory, Cluj University Press, Cluj-Napoca, 2008

[39] Rathee, S. and Reetu, Common fixed point and best approximation results for subcompatible mappings in hyperbolic ordered metric spaces, Creat. Math. Inform, 24 (2015), No. 1, 77-82

\author{
Department of Physics, Mathematics And Information Technologies \\ TIRASPOL STATE UNIVERSITY \\ GH. IABLOCIKIN 5., MD2069 CHIŞINĂU, REPUBLIC OF MOLDOVA \\ E-mail address: mmchobanegmail.com
}

